Authors' copy: Anwar McHenry, J \& Donovan, R. 2013. The Development of the Perth Charter for the Promotion of Mental Health and Wellbeing. International Journal of Mental Health Promotion. 15 (1): 58-64

\title{
The development of the Perth Charter for the Promotion of Mental Health and Wellbeing
}

\author{
Julia Anwar-McHenry $^{\mathrm{a}^{*}} \&$ Robert J Donovan ${ }^{\mathrm{b}}$ \\ ${ }^{a}$ School of Psychology and Speech Pathology, Curtin University, Perth, Australia \\ (previously at Mentally Healthy WA). \\ ${ }^{b}$ Mentally Healthy WA, Centre for Behavioural Research in Cancer Control, Curtin \\ University, Perth, Australia.
}

*Corresponding author: julia.anwarmchenry@curtin.edu.au

\begin{abstract}
The Perth Charter for the Promotion of Mental Health and Wellbeing is an initiative of the organising committee of the 7th World Conference on the Promotion of Mental Health and Prevention of Mental and Behavioural Disorders. An iterative feedback process was used to develop and revise the charter principles in consultation with health professionals. A final online survey showed strong support for each of the eight principles, which were rated 'essential' (as distinct from 'desirable' or 'not relevant') by 73-96\% of respondents. The principles were supported most strongly by practitioners, of whom $85-100 \%$ classified each as 'essential'. It is hoped that mental health professionals find the Charter useful for advocating for greater resource allocation in their jurisdictions to mental health, generally, and to mental health promotion in particular.
\end{abstract}

\section{Keywords}

mental health promotion, mental health, wellbeing, health promotion charter 
Authors' copy: Anwar McHenry, J \& Donovan, R. 2013. The Development of the Perth Charter for the Promotion of Mental Health and Wellbeing. International Journal of Mental Health Promotion. 15 (1): 58-64

\section{Introduction}

Given the ongoing impact of the Ottawa Charter for Health Promotion on policy and practice, particularly for physical health, the organising committee for the 7th World Conference on the Promotion of Mental Health and Prevention of Mental and Behavioural Disorders (held 17-19 October 2012 in Perth, Western Australia) decided to develop a Charter for the Promotion of Mental Health to mark the return of the international conference to Perth. Mindful that many such conference documents or 'declarations' simply fade away with little impact on policy or practice, the Perth Charter thus endeavoured to secure enduring relevance and application by: (a) being succinct with practical actionable content suitable for presentation to policy makers; (b) obtaining input from, and being supported by, a broad variety of stakeholders; and (c) being positioned as timely, progressive and important.

The Ottawa Charter (and its subsequent additions) constitutes an internationally recognised standard for health promotion and remains widely cited. While the Ottawa Charter promotes a holistic approach to health promotion, health promotion in practice has been largely confined to physical health promotion (Hawks, 2004). It was considered that a separate mental health promotion charter could be helpful as a first step towards the eventual integration of physical and mental health promotion. Thus, it was envisaged that the Perth Charter would do for mental health promotion what the Ottawa Charter did for health promotion generally - albeit primarily physical health promotion.

\section{Developing a Perth Charter for the Promotion of Mental Health}

The development of the Perth Charter was instigated by the organising committee of the 
Authors' copy: Anwar McHenry, J \& Donovan, R. 2013. The Development of the Perth Charter for the Promotion of Mental Health and Wellbeing. International Journal of Mental Health Promotion. 15 (1): 58-64

7th World Conference on the Promotion of Mental Health and Prevention of Mental and Behavioural Disorders. While the Clifford Beers Foundation coordinated feedback and input from the international community, the preliminary drafting of the Perth Charter principles was undertaken in Australia and was led by Professor Rob Donovan with support from staff of Mentally Healthy WA. There were three main phases in the development of the Perth Charter. The first phase comprised of consultation using qualitative methodologies with a broad representation of stakeholders, most of whom were based in Australia, to develop an initial draft set of Charter principles. The second phase involved the reduction, clarification and refinement of those draft principles from both direct feedback and feedback via on online survey from a broad representation of stakeholders. The third phase constituted the endorsement of the Perth Charter at the 2012 Conference and an ongoing commitment to revise and update the Charter on an annual basis. The procedure of each phase is described in more detail below.

Phase One was undertaken in two stages. In the first stage, two facilitated workshops with selected key stakeholders were held in Perth on 26 July (n=6) and 2 August $2012(n=5)$, These groups consisted of a diverse representation of health promotion practitioners, mental health consumers and carers, mental health service providers, policymakers, governance and funding bodies, academics, and researchers. Participants were invited through the conference organising committee members' networks and contacts through Mentally Healthy WA. Workshop participants were asked to consider the following questions: 'What was good about the Ottawa Charter?'(for example, it is simple with five action areas, three strategies, and an assertive call to action in specified areas (St Leger, 2007)), 'What were gaps or questions that remained following the creation of the Melbourne Charter for Mental 
Authors' copy: Anwar McHenry, J \& Donovan, R. 2013. The Development of the Perth Charter for the Promotion of Mental Health and Wellbeing. International Journal of Mental Health Promotion. 15 (1): 58-64

Health Promotion that needed to be addressed?', 'Why create another Charter?', 'What outcomes could be expected to be achieved through the creation of a charter?', and 'Would a manifesto, declaration, or statement be more appropriate to meet these aims?'

In the second stage of Phase One, a set of 10 potential Charter principles and an elaboration of each generated from these workshops were circulated via email to 50 individuals, including the workshop participants, selected international colleagues (through the assistance of the Clifford Beers Foundation), and Australian community representatives, local government, and sector representatives in sport, recreation, culture, and the arts. Input from such diverse groups was sought to ensure the final statements would be understandable by all and in a language suitable for political and community action. All participants were asked to comment on the relevance and wording of these principles, and invited to suggest additions, modifications or deletions. Those who had not participated in the workshops were asked when reviewing the principles, to consider the strengths and weaknesses of the Ottawa Charter for mental health promotion advocacy, as well as the impact and possible areas of unmet need from subsequent Charters, such as the Jakarta Charter, and the Melbourne Charter for Mental Health Promotion.

In Phase Two, the data collected in phase one were used to generate the first full draft of a Charter: a preamble; a vision; and eight principles, each with a brief supporting paragraph. An online questionnaire was developed to assess the acceptability or otherwise of each of the Charter components and principles, with the opportunity for respondents to provide alternative wordings, additional principles, or deletions. The online survey was conducted in two waves, with the second wave incorporating feedback from the first wave. The first online survey went live on 19 September 2012. 
Authors' copy: Anwar McHenry, J \& Donovan, R. 2013. The Development of the Perth Charter for the Promotion of Mental Health and Wellbeing. International Journal of Mental Health Promotion. 15 (1): 58-64

An invitation to participate in the survey was distributed via a snowball method that included the email and membership lists of the Clifford Beers Foundation, Mentally Healthy WA, and their extended networks. For the preamble, vision, and each of the principles respondents were asked to 'state whether you believe this principle is essential, desirable (but not essential), or not relevant for inclusion in the Perth Charter for Mental Health Promotion'. In addition, the survey provided a selection of potential names for the Perth Charter and asked, 'Which one of the following titles do you think is most appropriate for a charter that aims to advocate for mental health promotion to policy makers?'

Extensive feedback on the content, wording, and length of each principle resulted in a substantially revised set of seven principles that were made available for feedback via a second online survey that went live on 12 October 2012. As with survey one, a snowball method of recruitment was again used through the email and membership lists of the Clifford Beers Foundation and Mentally Healthy WA. Respondents who had provided a contact email following the completion of survey one were sent a direct email invitation to complete survey two. The question format for survey two was the same as for survey one.

The final phase involved the presentation of the Perth Charter along with the results of the second online survey at the closing plenary session of the Conference on 19 October 2012. Conference attendees were informed early in 2013, via email from the Clifford Beers Foundation, that the Perth Charter was available for download from the conference website. ${ }^{1}$ Participants were also informed that feedback provided by email to either the Clifford Beers Foundation or Mentally Healthy WA would continue to be incorporated in future updates of the Perth Charter. Therefore, phase three is an ongoing 
Authors' copy: Anwar McHenry, J \& Donovan, R. 2013. The Development of the Perth Charter for the Promotion of Mental Health and Wellbeing. International Journal of Mental Health Promotion. 15 (1): 58-64

stage in the Perth Charter's continued and future development. The Perth Charter is appended to this article.

\section{Support for the Perth Charter's Vision, Preamble and Principles}

The first online survey received 220 responses from 15 countries (71\% from Australia) with the sample comprising $41 \%$ practitioners (as distinct from researchers \& policy makers) and $44 \%$ involved primarily in mental health (as distinct from health promotion or public health, and others not primarily health related, such as education, etc.). The vision was considered 'essential' by $90 \%$ whilst the preamble attracted $73 \%$ 'essential'. Only $2 \%$ and $4 \%$ respectively considered each 'not relevant'. While there was moderate to strong support for each of the eight principles, with $69-90 \%$ of respondents (mean 79.75\%) rating each 'essential' (as distinct from 'desirable' or 'not relevant'), extensive comments and revisions suggested by the respondents led to a substantially revised and reduced set of seven principles.

These revised principles and a slightly modified preamble were assessed via a second online survey which received 117 responses from 15 countries $(75 \%$ from Australia), of which $44 \%$ were practitioners and 58\% represented the mental health sector. Relative to the first survey, there was stronger support for each of these revised principles, which were rated as 'essential' (as distinct from 'desirable' or 'not relevant') by $73-96 \%$ of respondents (mean $87.29 \%$ ) (see Table 1). Support for the vision (93\% 'essential') and preamble ( $82 \%$ 'essential') also were higher.

[Insert Table 1] 
Authors' copy: Anwar McHenry, J \& Donovan, R. 2013. The Development of the Perth Charter for the Promotion of Mental Health and Wellbeing. International Journal of Mental Health Promotion. 15 (1): 58-64

The principles were supported most strongly by practitioners, for whom the final principles were classified 'essential' by $85-100 \%$, and those working in mental health, for whom $75-96 \%$ classified the final principles as essential. Of the five alternative titles, the 'Perth Charter for the Promotion of Mental Health and Wellbeing' received the most support from respondents (47\% survey one, $53 \%$ survey two), followed by the 'Perth Charter for the Promotion of Mental Health' (21\% survey one, 26\% survey two).

\section{Conclusion}

Regardless of advances in a number of countries of the recognition of the disproportionate allocation of resources to physical and mental health, there is still a major gap between the rhetoric that supports holistic notions of health and action that allocates resources to interventions that address mental health in addition to physical health. Hence while some countries' policy makers may already acknowledge some of these Charter Principles, the distillation of these principles in a succinct internationally supported document can serve to hasten the translation of policy into practice. It is hoped that mental health professionals around the globe will find the Charter useful for presenting to political decision makers in their advocacy for greater resource allocation to mental health, generally, and to mental health promotion in particular. Finally, mindful of change, this Charter is proposed as a 'work-in-progress'. It is envisaged that the Charter will be updated on an annual basis. Individuals are therefore encouraged to provide continual feedback on the Perth Charter (to the first author or the Clifford Beers Foundation), especially with respect to policy makers' (and others') reactions to the Principles. 
Authors' copy: Anwar McHenry, J \& Donovan, R. 2013. The Development of the Perth Charter for the Promotion of Mental Health and Wellbeing. International Journal of Mental Health Promotion. 15 (1): 58-64

\section{Note}

${ }^{1}$ http://perth2012.org/charter.html

\section{References}

Hawks, S. (2004). Spiritual wellness, holistic health, and the practice of health education. American Journal of Health Education, 35(1), 11-16.

St Leger, L. (2007). Declarations, Charters, Statements - Their role in health promotion. Health Promotion International, 22(3), 179-181.

Table 1: Support for the final Perth Charter principles (survey two).

\begin{tabular}{l|c|c|c} 
& Essential & $\begin{array}{c}\text { Desirable, but } \\
\text { not essential }\end{array}$ & Not relevant \\
\cline { 2 - 4 } & $(\mathrm{n}=117)$ & $(\mathrm{n}=117)$ & $(\mathrm{n}=117)$ \\
$\%$ & $\%$ & $\%$ \\
\hline Vision & 93 & 7 & 0 \\
Preamble & 82 & 17 & 1 \\
Principle 1 & 96 & 4 & 0 \\
Principle 2 & 95 & 5 & 0 \\
Principle 3 & 93 & 7 & 0 \\
Principle 4 & 73 & 22 & 5 \\
Principle 5 & 77 & 13 & 10 \\
Principle 6 & 91 & 8 & 1 \\
Principle 7 & 86 & 14 & 0 \\
\hline
\end{tabular}




\title{
Perth Charter for the Promotion of Mental Health and Wellbeing
}

\author{
An outcome of the \\ Seventh World Conference on the Promotion of Mental Health and the \\ Prevention of Mental and Behavioural Disorders \\ October 17 - 19, Perth, Western Australia
}

\author{
Coordinated by the \\ Clifford Beers Foundation (UK) \\ and \\ Mentally Healthy WA \\ (Curtin University, Western Australia)
}


Authors' copy: Anwar McHenry, J \& Donovan, R. 2013. The Development of the Perth Charter for the Promotion of Mental Health and Wellbeing. International Journal of Mental Health Promotion. 15 (1): 58-64

\title{
Perth Charter for the Promotion of Mental Health and Wellbeing
}

\section{Our Vision: A world where mental health and physical health are equally valued}

\begin{abstract}
Preamble: The need for a mental health promotion charter
Despite the World Health Organisation's holistic definition of health, the mental, emotional, psychological and social components of this state of wellbeing receive limited attention. In particular, there is insufficient acknowledgement of the importance of these components to physical health, quality of life, and the need to protect and positively promote these components to enhance overall wellbeing. Similarly, while the principles of the Ottawa Charter are indeed relevant to mental health promotion, the implementation of health promotion has largely been confined to areas pertaining to physical health and injury prevention. Hence, despite the inseparable nature of physical and mental health, there is a need for a mental health promotion charter (that complements the principles of the Ottawa Charter) to allocate resources more equitably across physical and mental health. Given a number of governments in developed countries acknowledge the importance of enhancing population wellbeing, this Charter is timely to accelerate this attitude change and to ensure that policy moves beyond rhetoric to specific actions, particularly with respect to the social determinants of health and wellbeing.
\end{abstract}

Principle 1: Mental health is more than the absence of mental illness. Mental health promotion includes both preventing illness and increasing wellbeing. Good mental health is a protective factor for both physical and mental health outcomes. Good mental health not only enhances quality of life and wellbeing but also ensures greater resilience when individuals and communities are faced with stressors. It therefore makes good economic sense to build individual and community mental health and wellbeing from an early age and across the lifespan.

Principle 2: The foundations of social and emotional wellbeing develop in early childhood and must be sustained throughout the lifespan

Mental health starts at conception and is built on throughout the life cycle. In early childhood, children develop at a rapid rate in all spheres, including their social and emotional wellbeing. Mental health difficulties can be experienced and identified in early childhood, with evidence suggesting that half of mental health problems begin before the age of 14 . There are, therefore, significant personal, social, and economic benefits to be gained from a focus on promotion, prevention, and early intervention at this early stage of life.

Mental health promotion should be incorporated throughout the lifespan via activities in pre-school nurseries and settings, schools, colleges, universities, workplaces, other social institutions and community organisations. Further, in all areas of life and across all services there is a need for recognition that early intervention is imperative for the prevention of more serious problems developing. A comprehensive approach, therefore, requires cross-sectoral partnerships with government, private industry, and non-government organisations. This should include education, environment, transport, housing, workplaces and employment services, community services, alcohol and other drugs services, welfare organisations and emergency services, health support groups, religious organisations, and sporting, arts, and recreational groups. 
Authors' copy: Anwar McHenry, J \& Donovan, R. 2013. The Development of the Perth Charter for the Promotion of Mental Health and Wellbeing. International Journal of Mental Health Promotion. 15 (1): 58-64

\section{Principle 3: Mental health promotion must be integrated with public health and requires a cross-sectoral approach}

Given the strong relationship between mental health and issues such as substance abuse, self-harm and suicide, and various non-communicable diseases and their self-management, it is essential that mental health promotion be integrated into public health interventions. Similarly, social determinants such as homelessness, lack of education, poverty, violence, joblessness and job insecurity, discrimination, and so on, influence and are influenced by both mental and physical health. Thus, there is a need at a broader level to consider the social and emotional impact of all policy and planning decisions. Opportunities for mental health can be planned for proactively through mental health impact assessment across all sectors of civic society and public policy.

\section{Principle 4: Mental health and illness are constructed, experienced and viewed as different to physical health and illness.}

Despite the inseparability of physical and mental health, in reality more is known about physical health and illness than mental health and illness because far more is known about how the body works than is known about how the mind works. One key difference between mental and physical illness is the partly subjective nature of mental illness diagnosis and prognosis, and subsequent recommended and available treatments. Furthermore, far more is understood, researched, and discussed about mental illness than mental health. While physical health is discussed in preventative discourses such as exercise and nutrition, mental health discourse has inherently negative and illness connotations, such as a focus on psychoses, depression, and anxiety with little, if any, mention of the positive aspects of good mental health. The promotion of mental health and wellbeing must therefore work to reduce these real and perceived differences at all levels from the general public to the highest levels of government. There is also a need to increase resources for research to provide the evidence base for effective mental health promotion interventions.

\section{Principle 5: Mental health and mental illness are a dynamic balance.}

Mental health and illness should be thought of as two dimensions rather than a single continuum. Hence it is possible to experience periods of wellness in between episodes of illness. Mental health and illness is about ebb and flow, with independent fluctuations of levels of wellbeing and symptoms of illness from time to time. Thus a key consideration is how a mentally healthy balance can be managed and maintained over time and during periods of illness and recovery.

\section{Principle 6: Destigmatisation of mental illness and addressing discrimination are essential components of mental health promotion}

Stigma surrounding "mental health problems" and "mental illness" causes distress to those with a mental illness, inhibits help seeking by those in need, leads to discrimination against those with a mental illness, impedes recovery, and, importantly, obstructs the justification for, and communication and education about the positive messages of mental health promotion. Destigmatisation requires not only public education campaigns and education of the media, but the reorientation of all public services, including focused reorientation of mental health services, the enactment of disability, equalities and anti-discrimination legislation, and human rights.

\section{Principle 7: Mental health promotion must take place at the individual and societal levels.}

Mental health promotion includes the building of individual skills and coping strategies for increasing good mental health, increasing resilience to trauma, and assisting the management of and recovery from mental illness. Population-based and community programs should focus on the social environment and how individuals, families and communities can foster and maintain their own mental health and the mental health of those with whom they interact, in either a professional or social capacity. That is, given the opportunity, everyone can take actions to improve and maintain their own mental health and can influence the mental health and wellbeing of others. 